\title{
AVALIAÇÃO MICROBIOLÓGICA DO SOLO EM ÁREA IRRIGADA COM EFLUENTE DE LAGOA DE ESTABILIZAÇÃO
}

\author{
MICROBIOLOGICAL EVALUATION OF THE SOIL IN IRRIGATED AREA WITH \\ EFFLUENT POND STABILIZATION
}

\author{
RODRIGO C. BURBARELLI ${ }^{1}$ \\ MARTAS. GUILHERME PIRES² \\ BRUNO CORAUCCI FILHO ${ }^{*}$ \\ JOSÉ ROBERTO GUIMARÃES ${ }^{3}$ \\ ANTONIO ROBERTO SIVIERO ${ }^{4}$
}

\begin{abstract}
RESUMO
O presente trabalho avaliou a influência da aplicação de efluente de lagoa de estabilização anaeróbia no solo e as alterações em sua flora microbiana. Foram feitas análises de indicadores microbiológicos de poluição e alguns parâmetros físico-químicos solo. O efluente foi aplicado no solo de duas formas, diretamente da lagoa de estabilização e também após receber aplicação de cloro para a remoção de microrganismos. A técnica de aplicação utilizada foi a de sulcos rasos, como forma de pós-tratamento do efluente e teve como objetivo o reuso agrícola do efluente, ou seja, a utilização da água para irrigação e dos nutrientes presentes nesse efluente, principalmente nitrogênio e fósforo, pela cultura de milho (Zea mays). Os parâmetros microbiológicos monitorados no solo foram fungos totais e bactérias heterotróficas ou totais e os parâmetros físico-químicos foram pH no início e final do experimento e umidade do solo coletado. Os dados colhidos durante o desenvolvimento do projeto foram comparados com os índices estabelecidos pela legislação vigente e aspectos de saúde. Os resultados desta pesquisa recomendam a desinfecção dos efluentes para uso na forma de irrigação ou reuso.
\end{abstract}

Palavras-chaves: Lagoa anaeróbia, Solo.

\footnotetext{
1.Biólogo, Mestre em Engenharia Civil pela Universidade Estadual de Campinas.

2. Professora da Faculdade de Tecnologia, Departamento de Saneamento da Universidade Estadual de Campinas.

3.Professor da Faculdade de Engenharia Civil da Universidade Estadual de Campinas.

4. Professor do Colégio Técnico de Limeira da Universidade Estadual de Campinas.
} 


\section{ABSTRACT}

This study evaluated the influence of application of pond effluent anaerobic stabilization in the soil and changes in its microbial flora. Analysis were performed microbiological indicators of pollution and some physico-chemical soil. The effluent of stabilization pond was applied to the soil in two ways, directly and also after receiving the application of chlorine for the removal of microorganisms. The application technique used was a shallow grooves, as a form of post-treatment of effluent. Aimed to the agricultural reuse of effluent, ie the use of irrigation water and nutrients present in the effluent, mainly nitrogen and phosphorus by maize (Zea mays). The microbiological parameters were monitored in soil fungi and total heterotrophic bacteria or total and physical-chemical parameters were $\mathrm{pH}$ at the beginning and end of the experiment and soil moisture collected. The data collected during the development of the project were compared with the rates established by law and health aspects. The results of this study recommend the disinfection of effluent for use as irrigation or reuse.

Keywords: Stabilization pond, Soil, Reuse.

\section{INTRODUÇÃO}

A água residuária tratada pode ser utilizada de uma maneira planejada para diversas finalidades e essas práticas vêm crescendo ultimamente, principalmente devido à escassez dos recursos hídricos. Uma das maneiras de fazer o reuso das águas residuárias é sua utilização na agricultura, aproveitando também os nutrientes presentes nesse efluente.

No entanto, esse reuso de efluente pode ter como conseqüência a sua percolação para as camadas mais profundas do solo, podendo ocorrer a contaminação das águas subterrâneas e do solo por substâncias químicas, como também por microrganismos presentes no efluente, sendo necessária, portanto, uma investigação e monitoração destes parâmetros. A avaliação de características microbiológicas é de uso recente, envolvendo principalmente a presença ou ausência de coliformes fecais (THORN, 1992).

A aplicação de efluente oriundo de lagoa de estabilização utilizado no tratamento de esgoto doméstico no solo como forma de fertilização é interessante devido à presença de nutrientes indispensáveis para as plantas, como nitrogênio e fósforo. Por outro lado há também nesse tipo de efluente grande quantidade de microrganismos, muitos deles patogênicos, podendo estes contaminar o solo, pois sabe-se que os sistemas BioEng, Campinas, v.3 n.3, p.201-208, Set/Dez., 2009 de lagoas anaeróbias também possuem uma baixa remoção de patógenos (VON SPERLING, 1996).

Nesse trabalho foi feito um monitoramento do solo que recebeu aplicação de efluente da lagoa de estabilização. Os parâmetros microbiológicos monitorados no solo foram fungos totais e bactérias heterotróficas ou totais e os parâmetros físicoquímicos foram $\mathrm{pH}$ no início e final do experimento e umidade do solo coletado.

\section{MÉTODOS}

A área onde se desenvolveu o experimento desse projeto localiza-se no município de Limeira, o qual está situado a $154 \mathrm{~km}$ da capital, na região sudeste do estado de São Paulo, a $22^{\circ} 33^{\prime} 45^{\prime \prime}$ de latitude Sul e $44^{\circ} 24^{\prime} 09^{\prime \prime}$ de latitude Oeste. O terreno utilizado para a realização do experimento possui uma área de 7978,07 $\mathrm{m}^{2}$, fazendo divisa com a Estação de Tratamento de Esgotos Graminha (ETE Graminha), operada pela empresa Águas de Limeira, situado no bairro Graminha.

O experimento utilizou o efluente da lagoa de estabilização para irrigação por sulcos rasos de cultura de milho (Zea mays). O experimento foi conduzido em três safras, duas em período de 
seca e outra no período das chuvas. Na primeira safra foram aplicados no solo adubo e água tratada, e separadamente efluente de lagoa de estabilização anaeróbia, seguida por duas lagoas de maturação. Durante a segunda safra que foi cultivada no período de chuvas também foi aplicado efluente da lagoa desinfectado pelo método de cloração, que foi monitorado da mesma forma que foi realizado durante a primeira safra. A construção da área experimental obedeceu a critérios de projeto como taxas de aplicação, monitoramento e operação. As taxas de aplicação foram calculadas com base na caracterização do solo, para volumes de água suficientes para infiltrar no solo a profundidades de 0,20; 0,40 e 0,60 m, em parcelas destinadas a receber adubação e água, e efluente da lagoa anaeróbia (Fig. 1). Na segunda e terceira safras, mais três parcelas foram preparadas, uma para cada taxa de aplicação, que recebeu o efluente tratado por cloração.

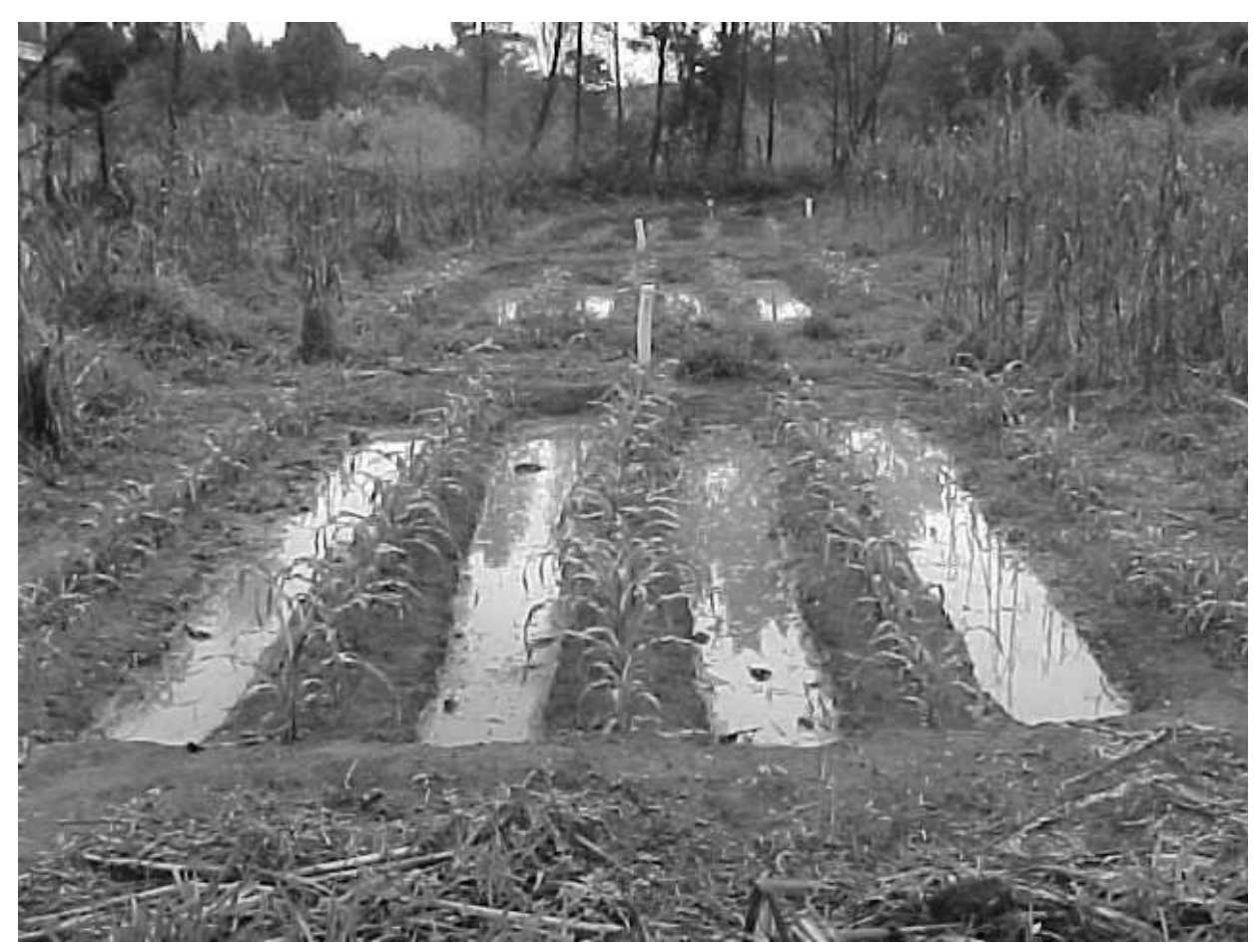

FIGURA 1 - Vista dos sulcos de irrigação

Em relação ao presente projeto, o milho utilizado para o plantio referente às três safras foi a variedade AG-405, Agroceres, de crescimento rápido, com ciclo de 120 dias.

\section{COLETAS E PREPARO DAS AMOSTRAS}

As coletas das amostras de solo foram realizadas na área superficial, através de amostras compostas de cinco pontos, coletadas a $15 \mathrm{~cm}$ de profundidade, de dentro de um dos sulcos de cada parcela. Concomitantemente com as coletas de água dos poços de monitoração.

As amostras de solo foram retiradas com auxílio de um trado, que foi desinfectado no campo com álcool $70 \%$ e água destilada, e armazenadas em sacos plásticos esterilizados, apropriados para coleta de solo.

Posteriormente, em laboratório, essas amostras foram dispostas em bandejas de polipropileno devidamente esterilizadas e os solos cuidadosamente homogeneizados com espátula esterilizada, e dispostas para a secagem em capela de fluxo laminar (SIVIERO,1995). Das porções de solo de cada parcela foram retiradas $10 \mathrm{~g}$ para teste de umidade e $10 \mathrm{~g}$ para as análises microbiológicas. A umidade do solo foi determinada BioEng, Campinas, v.3 n.3, p.201-208, Set/Dez., 2009 
pelo método gravimétrico de VIEIRA, (1983), citado por SIVIERO (1995).

\section{Técnica de contagem de microrganismos em placas "pour plate"}

Esta técnica consiste da inoculação de $1 \mathrm{~mL}$ da amostra na diluição desejada, seguida da aplicação do meio de cultura específico. Ela será utilizada nas análises de quantificação das bactérias heterotróficas do solo com o uso do meio de cultura Plate count Agar (PCA) bem como na quantificação de bolores totais do solo, utilizandose o meio de cultura Sabouraud dextrose agar. (CETESB L5.201, 1986)

\section{RESULTADOS E DISCUSSÃO}

Os resultados apresentados correspondem ao período de coletas realizadas a partir de junho a julho do ano seguinte. Este trabalho foi realizado através da análise de amostras do solo da área experimental durante três safras de milho, cada uma abrangendo um período de 120 dias. Duas delas durante a estação seca e uma durante a estação chuvosa. Também foi considerado o índice pluviométrico durante as três safras. A avaliação da influência das aplicações do efluente da lagoa anaeróbia, água e efluente desinfectado o solo, com relação a alguns parâmetros físico-químicos e principalmente microbiológicos, foi aplicado um tratamento estatístico nos dados utilizando-se o método da comparação de médias de duas amostras. Para o solo foi comparada cada parcela de cada tipo de tratamento, ou cenário, com sua respectiva em paralelo.

\section{Bactérias heterotróficas e Fungos totais}

A aplicação de efluente no solo não mostrou diferenças significativas entre as parcelas água e efluente nem no período de seca e nem no chuvoso. Como foi citado, a introdução de uma comunidade microbiana alóctone, em um ambiente onde já existe outra estabelecida, acarreta na eliminação dos microrganismos introduzidos. Isso ocorre devido às características ambientais às quais a comunidade autóctone já está adaptada. Os resultados obtidos para bactérias heterotróficas e fungos totais estão apresentados nas Tab. 1 e 2. A comunidade introduzida não chega a crescer, permanecendo em estado latente, e termina por ser eliminada pela ação predatória de protozoários e também por relações ecológicas de antagonismo, parasitismo e competição por nutrientes (ALEXANDER, 1977).

Tabela 1 - Resultados de Bactérias Heterotróficas do solo UFC/g

\begin{tabular}{|c|c|c|c|c|c|c|c|c|c|}
\hline $\begin{array}{c}\text { DATA } \\
\text { DA } \\
\text { COLETA }\end{array}$ & A 20 & A 40 & A 60 & E 20 & E 40 & E 60 & D 20 & D 40 & D 60 \\
\hline $12 / 06 / 03$ & $>10^{6}$ & $>10^{6}$ & $1,00 \times 10^{6}$ & $>10^{6}$ & $3,50 \times 10^{6}$ & $>10^{6}$ & & & \\
\hline $17 / 07 / 03$ & $<10^{6}$ & $1,00 \times 10^{6}$ & $<10^{6}$ & $1,00 \times 10^{6}$ & $1,00 \times 10^{6}$ & $1,00 \times 10^{6}$ & & & \\
\hline $29 / 07 / 03$ & $1,00 \times 10^{6}$ & $<10^{6}$ & $<10^{6}$ & $1,00 \times 10^{6}$ & $1,00 \times 10^{6}$ & $<10^{6}$ & & & \\
\hline $27 / 08 / 03$ & $<10^{6}$ & $5,00 \times 10^{5}$ & $5,00 \times 10^{5}$ & $5,00 \times 10^{5}$ & $3,50 \times 10^{6}$ & $1,00 \times 10^{6}$ & & & \\
\hline 29/09/03 & $2,00 \times 10^{4}$ & $<10^{4}$ & $8,00 \times 10^{4}$ & $1,50 \times 10^{4}$ & $8,00 \times 10^{4}$ & $7,00 \times 10^{4}$ & & & \\
\hline $21 / 01 / 04$ & $6,50 \times 10^{4}$ & $4,50 \times 10^{4}$ & $8,00 \times 10^{4}$ & $5,50 \times 10^{4}$ & $4,00 \times 10^{4}$ & $7,00 \times 10^{4}$ & $6,00 \times 10^{4}$ & $5,50 \times 10^{4}$ & $6,50 \times 10^{4}$ \\
\hline $11 / 02 / 04$ & $1,10 \times 10^{5}$ & $8,00 \times 10^{4}$ & $2,10 \times 10^{5}$ & $1,30 \times 10^{5}$ & $4,10 \times 10^{6}$ & $4,60 \times 10^{5}$ & $6,1 \times 10^{4}$ & $3,80 \times 10^{4}$ & $5,00 \times 10^{4}$ \\
\hline $17 / 02 / 04$ & $2,10 \times 10^{5}$ & $1,20 \times 10^{5}$ & $3,30 \times 10^{5}$ & $1,00 \times 10^{5}$ & $5,20 \times 10^{6}$ & $5,60 \times 10^{5}$ & $7,20 \times 10^{4}$ & $2,20 \times 10^{5}$ & $3,20 \times 10^{5}$ \\
\hline 03/05/04 & $6,00 \times 10^{4}$ & $6,00 \times 10^{4}$ & $7,50 \times 10^{4}$ & $2,45 \times 10^{5}$ & $9,00 \times 10^{4}$ & $1,00 \times 10^{5}$ & $7,00 \times 10^{4}$ & $7,50 \times 10^{4}$ & $1,90 \times 10^{5}$ \\
\hline $14 / 07 / 04$ & $3,00 \times 10^{5}$ & $1,00 \times 10^{5}$ & $2,00 \times 10^{5}$ & $5,50 \times 10^{5}$ & $3,00 \times 10^{5}$ & $8,50 \times 10^{5}$ & $2,50 \times 10^{5}$ & $4,00 \times 10^{5}$ & $6,50 \times 10^{5}$ \\
\hline
\end{tabular}


Tabela 2 - Resultados de Fungos totais (UFC/g) das amostras de solo

\begin{tabular}{c|c|c|c|c|c|c|c|c|c}
\hline $\begin{array}{c}\text { DATA } \\
\text { DA } \\
\text { COLETA }\end{array}$ & A 20 & A 40 & A 60 & E 20 & E 40 & E 60 & D 20 & D 40 & D 60 \\
\hline $12 / 06 / 03$ & $1,03 \times 10^{4}$ & $4,30 \times 10^{3}$ & $1,63 \times 10^{4}$ & $<10^{3}$ & $1,35 \times 10^{4}$ & $8,5 \times 10^{3}$ & & & \\
$17 / 07 / 03$ & $4,50 \times 10^{3}$ & $2,00 \times 10^{3}$ & $3,50 \times 10^{3}$ & $3,00 \times 10^{3}$ & $<10^{3}$ & $5,00 \times 10^{3}$ & & \\
$29 / 07 / 03$ & $1,65 \times 10^{5}$ & $4,50 \times 10^{4}$ & $5,50 \times 10^{4}$ & $1,10 \times 10^{5}$ & $2,30 \times 10^{5}$ & $2,50 \times 10^{4}$ & & \\
$27 / 08 / 03$ & $2,00 \times 10^{4}$ & $4,00 \times 10^{4}$ & $1,50 \times 10^{4}$ & $2,50 \times 10^{4}$ & $1,00 \times 10^{5}$ & $3,50 \times 10^{4}$ & & \\
$29 / 09 / 03$ & $5,00 \times 10^{4}$ & $8,00 \times 10^{4}$ & $4,50 \times 10^{4}$ & $3,00 \times 10^{4}$ & $1,00 \times 10^{5}$ & $4,80 \times 10^{5}$ & & & \\
$21 / 01 / 04$ & $5,80 \times 10^{4}$ & $1,25 \times 10^{5}$ & $1,35 \times 10^{5}$ & $9,20 \times 10^{5}$ & $6,50 \times 10^{5}$ & $5,50 \times 10^{5}$ & $7,20 \times 10^{5}$ & $8,80 \times 10^{5}$ & $4,50 \times 10^{5}$ \\
$11 / 02 / 04$ & $1,40 \times 10^{5}$ & $4,70 \times 10^{5}$ & $4,20 \times 10^{5}$ & $8,60 \times 10^{4}$ & $1,00 \times 10^{5}$ & $6,10 \times 10^{4}$ & $6,10 \times 10^{4}$ & $3,80 \times 10^{4}$ & $5,00 \times 10^{4}$ \\
$17 / 02 / 04$ & $3,80 \times 10^{4}$ & $1,50 \times 10^{4}$ & $4,00 \times 10^{4}$ & $1,60 \times 10^{4}$ & $3,10 \times 10^{4}$ & $1,50 \times 10^{4}$ & $1,60 \times 10^{4}$ & $6,20 \times 10^{4}$ & $3,10 \times 10^{4}$ \\
$03 / 05 / 04$ & $2,70 \times 10^{4}$ & $2,00 \times 10^{4}$ & $1,70 \times 10^{4}$ & $1,90 \times 10^{4}$ & $6,50 \times 10^{3}$ & $4,50 \times 10^{4}$ & $2,10 \times 10^{4}$ & $1,90 \times 10^{4}$ & $1,20 \times 10^{4}$ \\
$14 / 07 / 04$ & $1,30 \times 10^{6}$ & $4,00 \times 10^{5}$ & $7,50 \times 10^{5}$ & $1,45 \times 10^{6}$ & $1,35 \times 10^{6}$ & $1,00 \times 10^{6}$ & $1,10 \times 10^{6}$ & $1,65 \times 10^{6}$ & $2,05 \times 10^{6}$ \\
\hline
\end{tabular}

As parcelas foram comparadas em paralelo, onde A2, D2 e E2 representam as parcelas de aplicação de água, efluente, e efluente desinfectado com taxa de $0,2 \mathrm{~m}$, respectivamente. $0,40 \mathrm{~m}$ e $0,60 \mathrm{~m}$.

O mesmo para as taxas de aplicação de

A comparação estatística das médias das amostras mostrou diferenças significativas entre as parcelas de efluente desinfectado com relação às parcelas E2 e D2, E4 e D4 e também A2 e D2 (Tabela. 3). Essa diferença com relação ao efluente desinfectado pode estar relacionada à presença de cloro residual, visto que o número de bactérias heterotróficas por grama de solo nas parcelas de efluente desinfectado foi menor do que nas demais parcelas.

TABELA 3 - Comparação entre as parcelas de aplicação nos três cenários para o parâmetro bactérias heterotróficas

\begin{tabular}{l|c|c|c|c|c|c|c|c|c}
\hline \multicolumn{1}{c}{ BACTÉRIAS HETEROTRÓFICAS DO SOLO- UFC/g } \\
\hline & A2-E2 & A4-E4 & A6-E6 & E2-D2 & E4-D4 & E6-D6 & A2-D2 & A4-D4 & A6-D6 \\
\hline Total & $\mathrm{N}$ & $\mathrm{N}$ & $\mathrm{N}$ & $\mathrm{D}$ & $\mathrm{D}$ & $\mathrm{N}$ & $\mathrm{D}$ & $\mathrm{N}$ & $\mathrm{N}$ \\
\hline Seca & $\mathrm{N}$ & $\mathrm{N}$ & $\mathrm{N}$ & $\mathrm{N}$ & $\mathrm{N}$ & $\mathrm{N}$ & $\mathrm{N}$ & $\mathrm{N}$ & $\mathrm{N}$ \\
\hline Chuva & $\mathrm{N}$ & $\mathrm{N}$ & $\mathrm{N}$ & $\mathrm{N}$ & $\mathrm{N}$ & $\mathrm{D}$ & $\mathrm{N}$ & $\mathrm{N}$ & $\mathrm{N}$ \\
\hline
\end{tabular}

Obs: $\mathrm{N}$ : os resultados não diferem com nível de significância com $\mathrm{P}=0,05$

D: os resultados diferem com nível de significância com $\mathrm{P}=0,05$

Com relação aos fungos totais, não houve diferença significativa na análise estatística das médias dos valores obtidos (Tabela 4). Estes valores estiveram entre 103 e 106, normalmente encontrados utilizando-se a técnica de contagem de microrganismos do solo em placas (SIVIERO, 1995).

TABELA 4 - Comparação entre as parcelas de aplicação nos três cenários para o parâmetro de fungos totais

\begin{tabular}{c|c|c|c|c|c|c|c|c|c}
\hline \multicolumn{1}{c}{ FUNGOS TOTAIS DO SOLO - UFC/g } \\
\hline & A2-E2 & A4-E4 & A6-E6 & E2-D2 & E4-D4 & E6-D6 & A2-D2 & A4-D4 & A6-D6 \\
\hline Total & $\mathrm{N}$ & $\mathrm{N}$ & $\mathrm{N}$ & $\mathrm{N}$ & $\mathrm{N}$ & $\mathrm{N}$ & $\mathrm{N}$ & $\mathrm{N}$ & $\mathrm{N}$ \\
\hline Seca & $\mathrm{N}$ & $\mathrm{N}$ & $\mathrm{N}$ & $\mathrm{N}$ & $\mathrm{N}$ & $\mathrm{N}$ & $\mathrm{N}$ & $\mathrm{N}$ & $\mathrm{N}$ \\
\hline Chuva & $\mathrm{N}$ & $\mathrm{N}$ & $\mathrm{N}$ & $\mathrm{N}$ & $\mathrm{N}$ & $\mathrm{N}$ & $\mathrm{N}$ & $\mathrm{N}$ & $\mathrm{N}$ \\
\hline
\end{tabular}

Obs: $\mathrm{N}$ : os resultados não diferem com nível de significância com $\mathrm{P}=0,05$

$\mathrm{D}$ : os resultados diferem com nível de significância com $\mathrm{P}=0,05$ 
As Figuras 2 a 5 representam os valores dos três tipos de tratamento no solo nas três taxas de aplicação de efluente no solo referentes à bactérias heterotróficas e fungos totais, respectivamente. Com base nos dados obtidos tanto para fungos como para bactérias heterotróficas, pode-se dizer que a aplicação de esgoto doméstico não afetou significativamente a flora microbiana presente no solo.

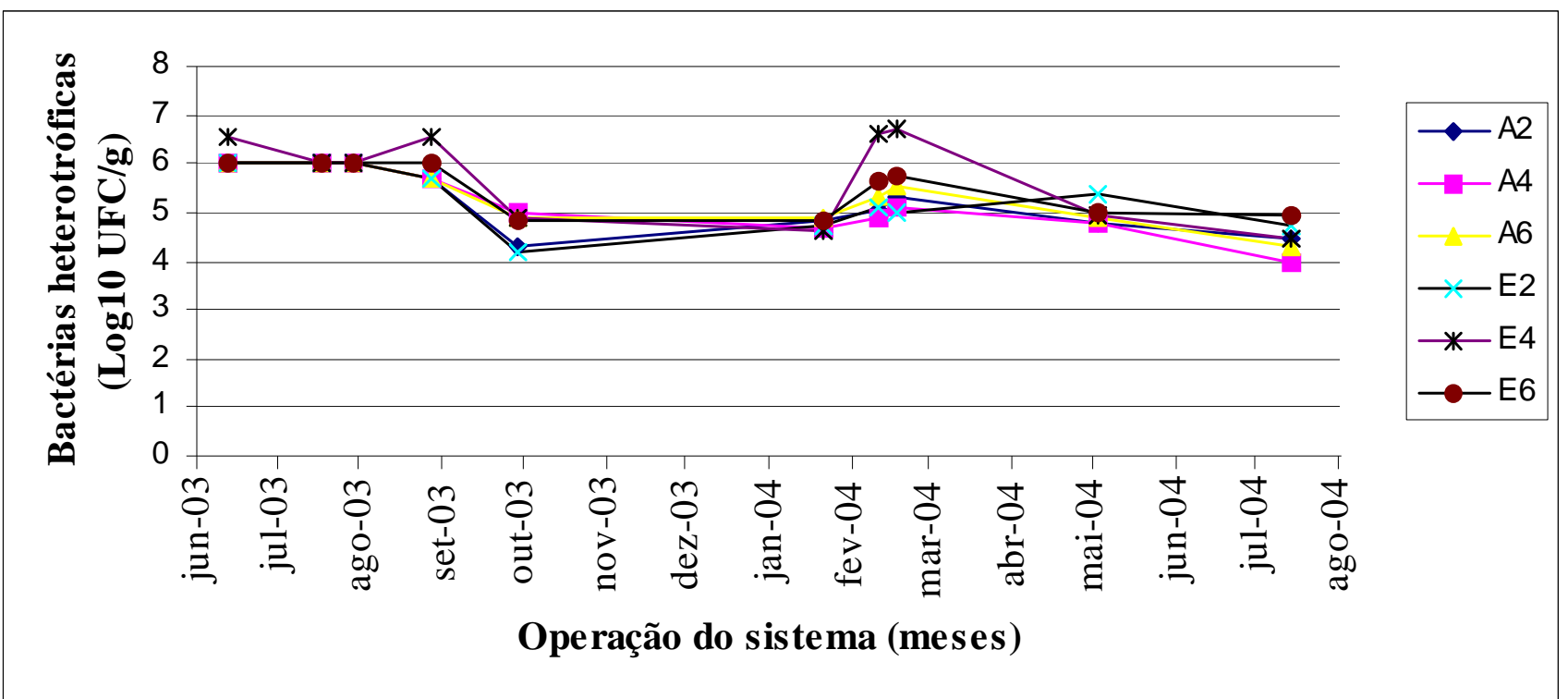

FIGURA 2 - Parcelas de solo do cenário água comparadas às parcelas do cenário efluente para o parâmetro bactérias heterotróficas

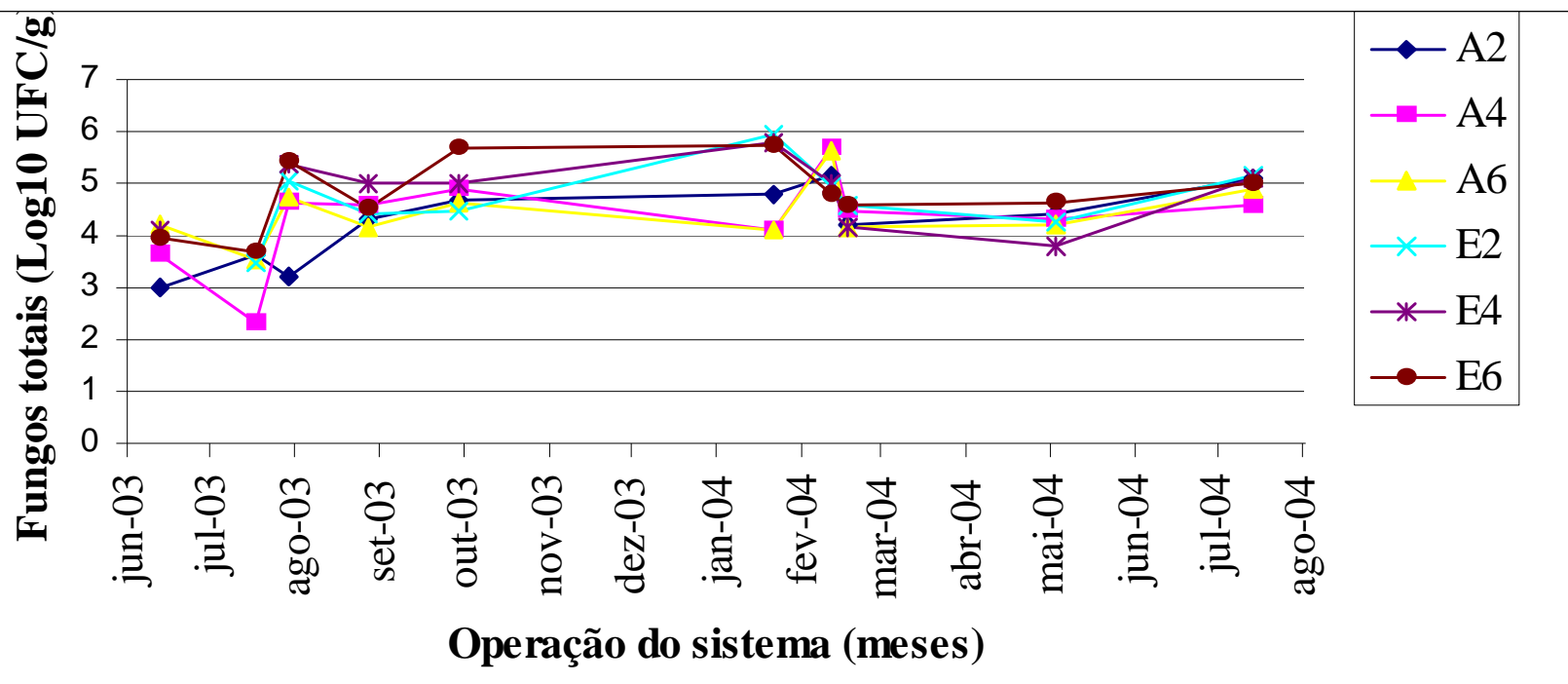

FIGURA 3 - Parcelas de solo do cenário água comparadas às parcelas do cenário efluente para o parâmetro fungos totais 


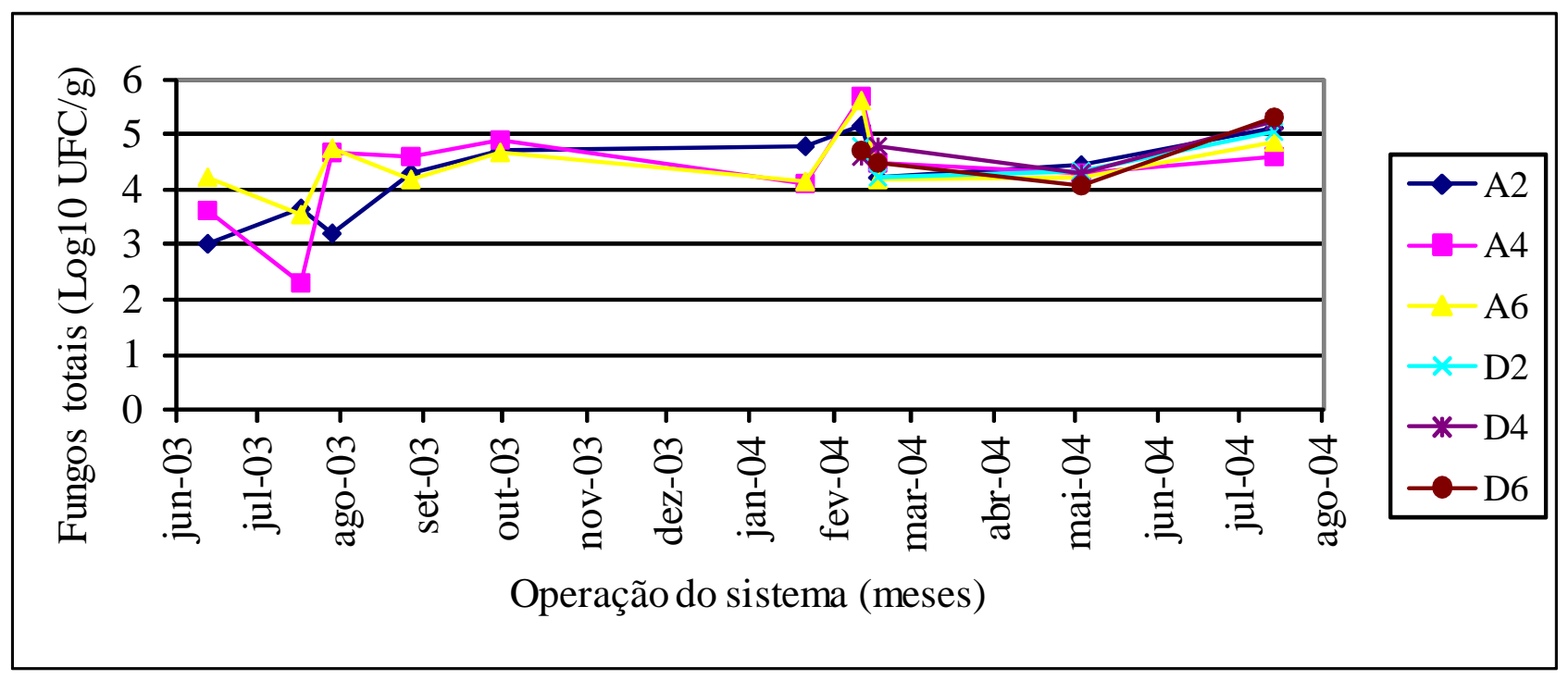

FIGURA 4 - Parcelas de solo do cenário água comparadas às parcelas do cenário efluente desifectado para o parâmetro fungos totais

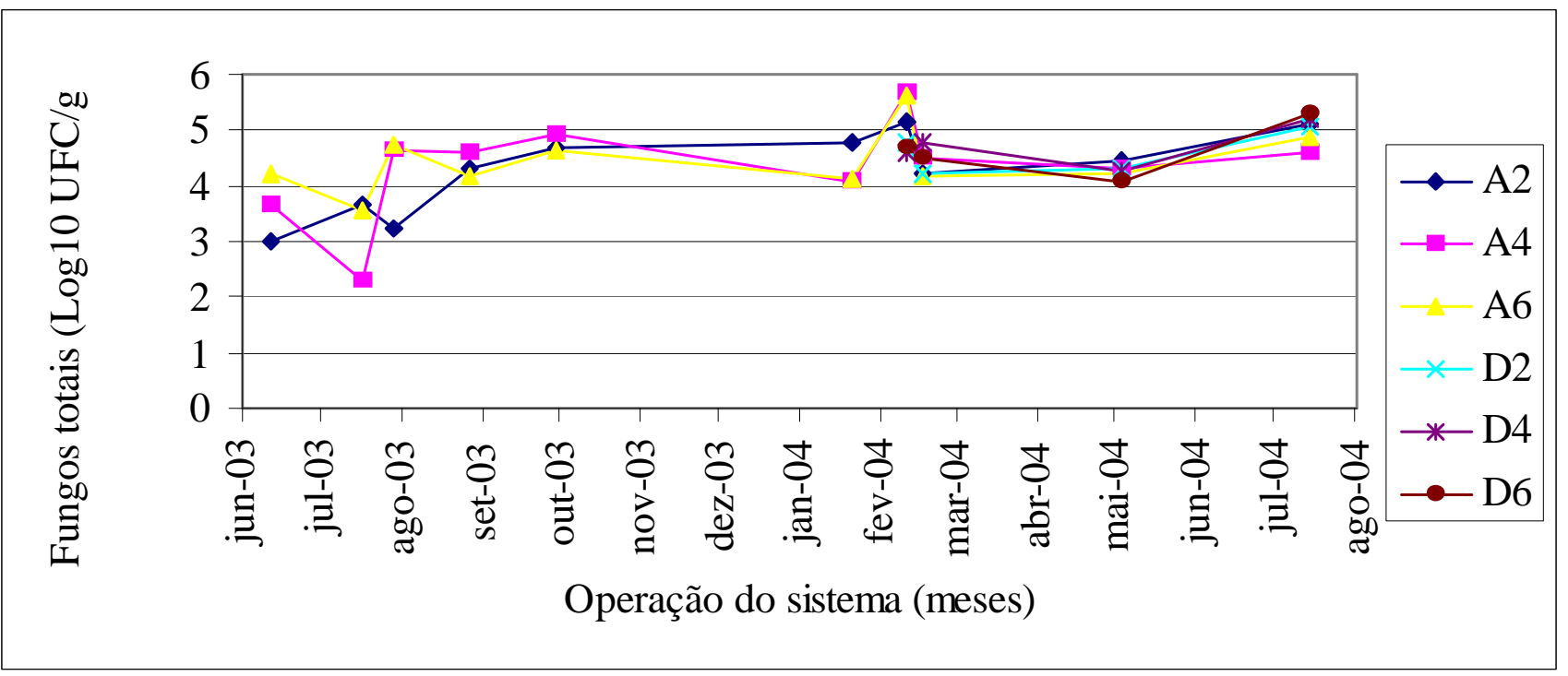

FIGURA 5 - Parcelas de solo do cenário água comparadas às parcelas do cenário efluente desinfetado para o parâmetro fungos totais

Os microrganismos do solo analisados no presente trabalho, bactérias heterotróficas e fungos totais, não demonstraram sofrer influência significativa em decorrência da aplicação de efluente no solo, onde provavelmente atuaram eliminando a microflora introduzida e convertendo a matéria orgânica presente no efluente para formas acessíveis ao milho.

Os parâmetros físico-químicos analisados, como $\mathrm{pH}$ umidade do solo, não apresentaram diferenças significativas ou influência direta sobre os microrganismos analisados.

\section{REFERÊNCIAS BIBLIOGRÁFICAS}

ALEXANDER, M. Introduction to soil microbiology. 2.ed. New York: John-Wiley \& Sons, 1977. $467 p$.

BioEng, Campinas, v.3 n.3, p.201-208, Set/Dez., 2009 
COMPANHIA DE TECNOLOGIA DE SANEAMENTO AMBIENTAL - CETESB . Análises microbilógicas de águas, L5.201 : bactérias heterotróficas: contagem em placas. São Paulo: CETESB, 1986. 11p. Normalização Técnica Saneamento Ambiental,_(Normalização. Técnica L5.201).

SIVIERO, A.R. Influência da aplicação no solo do resíduo da indústria cítrica sobre fungos e bactérias e avaliação da sua toxicidade sobre Daphinia similis. 1995. 112p. Tese (Doutorado em Microbiologia) - Universidade Estadual de São Paulo, Rio Claro

THORN,R.H.; COXON,C.E. Hidrogeological aspects of bacterial contamination of some western Ireland karstic limestone aquifers. Environmental Geological and Water Science, v. 20, n. 1, p. 65$72,1992$.

VON SPERLING, M. Lagoas de estabilização. Belo Horizonte: Departamento de Engenharia Sanitária e Ambiental, Universidade Federal de Minas Gerais - UFMG, v. 3, 1996, 136 p. 